Research Paper

\title{
A Study on needs for e-learning - Through the analysis of national survey and case studies
}

\author{
Keiko WATANABE \\ National Institute of Informatics
}

\begin{abstract}
The needs of Japanese universities and learners for e-learning are mainly focused on in this study. First, e-learning cases are classified into three categories: type I , correspondence courses where students can obtain credits and/or degrees mainly based on e-learning; type II, on-campus courses where students can obtain some credits based on e-learning; and type III, on-campus courses where the faculty uses e-learning tools as a supplemental measure of their classes. A Survey conducted by National Institute of Multimedia Education clearly shows that the needs of universities for type III is comparatively high. Based on case studies, this paper clarifies the following two points: first, students such as working students, foreign students, and those who study specialized areas are the main beneficiaries of types I and II ; second, all types meet students' needs by improving the qualities of classes. It seems reasonable to conclude that type III is expected to become the most popular model of e-learning because it responds to the needs of students and universities and that promotion of type I and/or II is possible if universities are successful in providing curriculums that suit the needs of potential students.
\end{abstract}

\section{KEYWORDS}

Japanese higher education, e-learning, needs, faculty development, potential students

\section{Background and purpose of research}

At Japanese universities, the term "e-learning" has come to be used not only as one of many research themes but also as one of the educational methods that can be adopted by each university.

E-learning has been deregulated in stages. It became possible in 1998 to give classes interactively and simultaneously by using videoconferencing based on satellite communications. It then became possible in 2001 to give classes interactively by using the Internet and/or other information technologies, although such classes do not have to be run simultaneously.

There is an extensive literature on e-learning published from around 2000. Porter [1], Sato [2], Kasaki [3], and Yoshida [4] introduce advanced practices regarding e-learning in the U.S.A. Araki [5] and

Received May 27, 2005; Revised Sepember 29, 2005; Accepted September 30, 2005.

keiko@nii.ac.jp

DOI : 10.2201/Niipi.2005.2.6
Morita [6] predict that e-learning will develop new educational methods, will increase opportunities for learning, or will increase educational effectiveness. Horton teaches the detailed know-how to introduce e-learning [7]. Proposers of Virtual University Research Forum [8], Obara [9], Advanced Learning Infrastructure Consortium (ed.) [10], and AML II Project at Aoyama Gakuin University Research Institute [11] introduce experimental practices at universities.

On the other hand, e-learning has come to play an important role as a method to provide university education across national borders mainly in Europe, the U.S.A., and Australia. Considering this circumstance, a report by the Consultative Council regarding Global Quality Assurance of Universities (hereinafter called the "Consultative Council") has proposed that Japanese universities should also actively introduce e-learning in order to survive global competition [12].

In addition, e-learning systems have been developed as a research subject in many universities. The faculty 
has been seeking to apply these systems experimentally to real classes as educational tools.

Besides, the National Institute of Multimedia Education (hereinafter called "NIME") provides necessary assistance for e-learning diffusion. For example, NIME is carrying out research to develop and distribute multimedia educational materials, including studies on how copyrights should be handled. NIME is also developing a program to build e-learning sites and is distributing that program free of charge.

However, even under these circumstances surrounding e-learning, we have to say that Japanese universities have not yet actively promoted full-scale introduction of e-learning. This situation seems to be due to the fact that universities or learners do not have needs for e-learning, which might be a key driver to the introduction of e-learning, or that they have not realized that their needs actually exist.

Some researchers have made experimental practices to introduce e-learning and have urged the necessity of spreading e-learning. If the present time is a transitional period in which e-learning is being spread as an educational method that can be adopted by each university, studies that focus on universities' or learners' needs for e-learning will be also important. The literature on e-learning is, however, confined to such books mentioned above so far and empirical research on the needs for e-learning has not been accumulated. This paper tries to deal with such a task.

Based on the above-mentioned background and purpose, this paper firstly gives a definition of "e-learning" in order to study broadly actual cases in various universities. Then, the cases of e-learning are classified into the categories which would be necessary to study the needs of universities and students for the full-scale e-learning. Then this paper clarifies the trend of needs in each categories based on National Survey on ICT Use in Higher Education Institutions in Japan conducted by NIME, and discusses empirically needs and characteristics in each categories based on case studies. Finally, this paper mentions some future views about e-learning at universities concluded from the whole argument.

\section{Definition of "e-learning"}

Although the term "e-learning" has been used frequently in Japan since around 2000, people who discuss "e-learning" are still using various different definitions of the term. Some people define e-learning as "distance education using the Internet and/or other information technologies." The Consultative Council used this definition [12]. On the other hand, some other people say, "E-learning is a self-learning process using IT communication networks and other means.

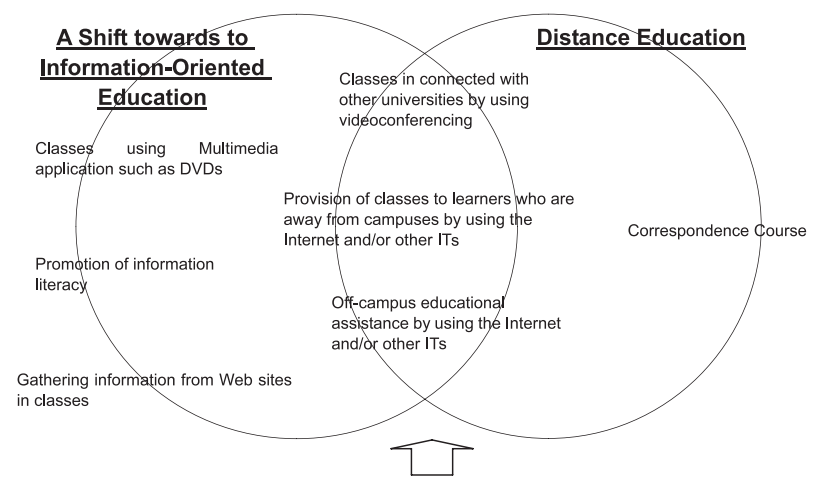

Distance education using the Internet and/or other information technologies ("e-learning")

Fig. 1 Difinition of "e-learning"

The contents of e-learning programs are edited in line with the purpose of learning, and it is necessary to secure interaction between learners and those who provide the contents. The term "interaction" used here refers to practices in which learners are given opportunities to participate according to their own intentions and timely provided appropriate instructions to carry forward learning by people and/or computers." The Advanced Learning Infrastructure Consortium used this definition [13]. This definition of e-learning places emphasis on interaction between learners and those who provide educational contents, instead of focusing on distance education. But both of these definitions assume the use of not only computers but also network technologies.

This paper uses a broader definition of e-learning since it aims to inclusively cover various practices made by universities, especially full-scale, universitywide practices and practices that can be properly positioned as systems.

Although this paper defines e-learning as "distance education using the Internet and/or other information technologies," a broader definition of the term "distance education" is used, instead of adopting the conventional practice to regard distance education as a "correspondence course." The term "distance education" as used in this paper includes education, learning and/or educational support practices that became available outside campuses owing to the development of computer and network technologies (such as the Internet, satellite communications, and videoconferencing; see Fig.1).

\section{Framework of analysis-Aattempt to classify e-learning practices}

This paper, which assumes the broader definition of 
Table 1 Examples of each type of e-learning

\begin{tabular}{ll}
\hline Type I & So-called "virtual universities" \\
\hline Type II & Cooperative classes based on e-learning between Japanese universities \\
& and universities in other Asian countries. \\
& - Cooperative classes base- on e-learning among university consortiums. -- \\
& E-learning-based classes of general education courses at universities that \\
& have two or more campuses. \\
\hline Type III & Learning support activities with course management tools: such as post- \\
& ing of teaching materials on Web sites; posting of teachers' messages or \\
& assignments; acceptance of questions from students; and provision of \\
& electrical bulletin boards for discussions.
\end{tabular}

e-learning, classifies e-learning practices into four categories from the institutional viewpoint in order to study needs of universities and learners.

The institutional viewpoint focuses on the following two points:

(a) whether e-learning programs are adopted by on-campus courses or correspondence courses; and,

(b) whether learners can earn credits mainly based on e-learning programs or not.

E-learning practices can be classified into the following four categories based on these two points.

(1) correspondence courses in which students can obtain credits and/or degrees mainly based on e-learning.

(2) correspondence courses in which universities can not give credits and/or degrees to students based on e-learning.

(3) on-campus courses in which students can obtain some credits based on e-learning.

(4) on-campus courses in which the faculty use e-learning tools as a supplemental measure of their classes.

In this paper, practices classified as category (2) are not studied, because that category, which includes extension courses, can not be regarded as formal university education.

As a result, categories (1), (3), and (4) are hereinafter referred to as type I, type II, and type III in this paper (see Table 1).

The reason the analysis in this paper is based on the above classification is that it would be appropriate to suppose that there are different needs of universities and/or students in regards to e-learning, each type of which has a different educational function.

Accordingly, the analysis in this paper was done according to this classification.

\section{Analysis based on NIME's survey}

NIME has been carrying out National Survey on ICT Use in Higher Education Institutions in Japan (hereinafter called the "Survey") annually since fiscal 1999 [14]. This chapter aims to clarify based on the Survey the actual situation of e-learning practices and future needs for e-learning at universities for each of the three types.

The actual situation of e-learning practices at each university is shown by The Use of Multimedia and ICT (see Fig.2).

"Conducting administrative communication by e-mail or bulletin boards," "Submitting class assignments by e-mail or bulletin boards," "Receiving questions from students by e-mail or on bulletin boards," "Posting course information (syllabi, resumes, class schedules) on the Web," and "Supplementing class discussion by e-mail or bulletin boards" are seen quite frequently, while these activities are assumed to be done in type III cases. On the other hand, the percentage of frequent use of activities such as "Broadcasting courses by satellite communications," "Posting streaming video of lectures on the Web," and " Offering credits bearing online courses" is about $10 \%$ or less, while these activities are assumed to be done in type I and/or type II cases.

Regarding future plans for internet use at each university, needs for activities related to type III are rather strong. On the other hand, the percentage related to the level of future needs for activities such as "International exchange with students oversea," "Posting streaming videos of courses on the Web," "Offering classes in a credit transfer system with other institutions," and "Providing credit-bearing online courses" is less than $20 \%$, while these activities are related to type I and/or II (see Fig. 3).

It is clear that activities related to type III are currently seen to a certain degree, and there are rather 

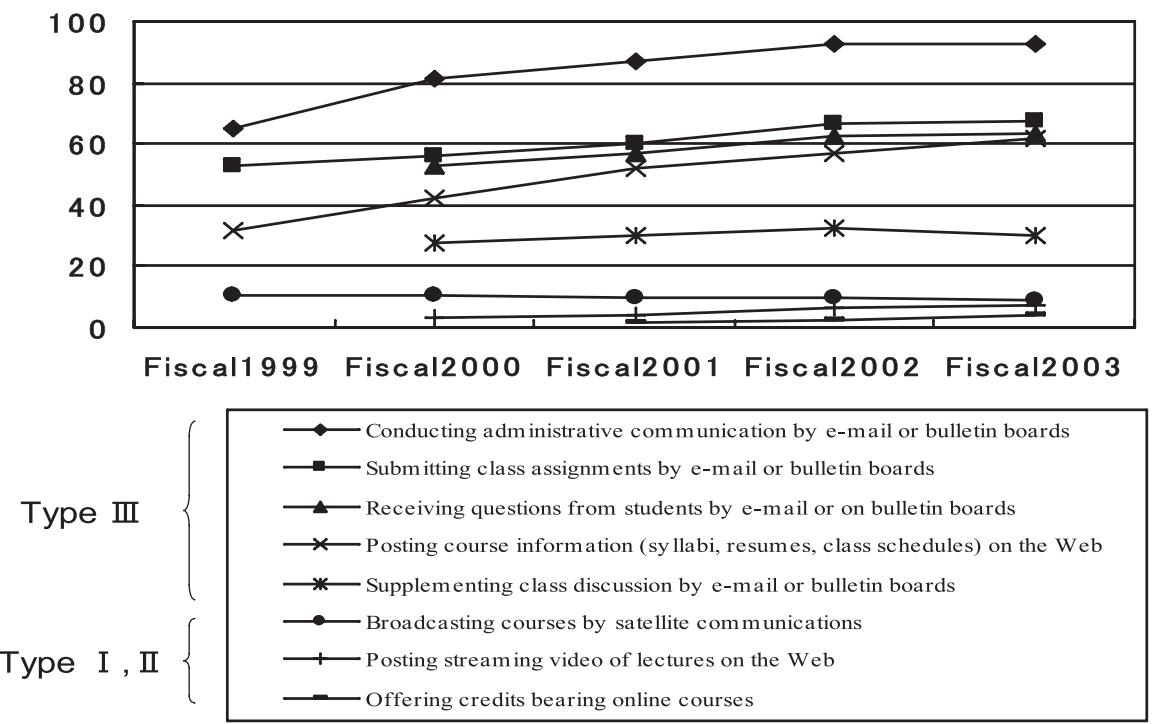

Notes: 1 This figure is drawn up by rearranging the National Survey on ICT Use in Higher education Institutions in Japan conducted by NIME in line with the classification in this paper.

2 This figure is drawn up according to data for universities, though the Survey covers data for universities, junior colleges, and technical colleges.

Fig.2 The use of multimedia and ICT (“Used a lot + Used to some exatet”(\%)).

strong needs for such activities in the future. Even if such activities are currently being done individually by each faculty, the necessity to improve the security of systems and to maintain the records of correspondence with students seems to be growing. As a result, it can be said that there is a high tendency to carry out sys- tematic practices by using course-management tools. In other words, when such tools are introduced, they are expected to be used actively.

On the other hand, activities related to types I and II are not being done actively, and there are not strong needs for such activities in the future. According to the

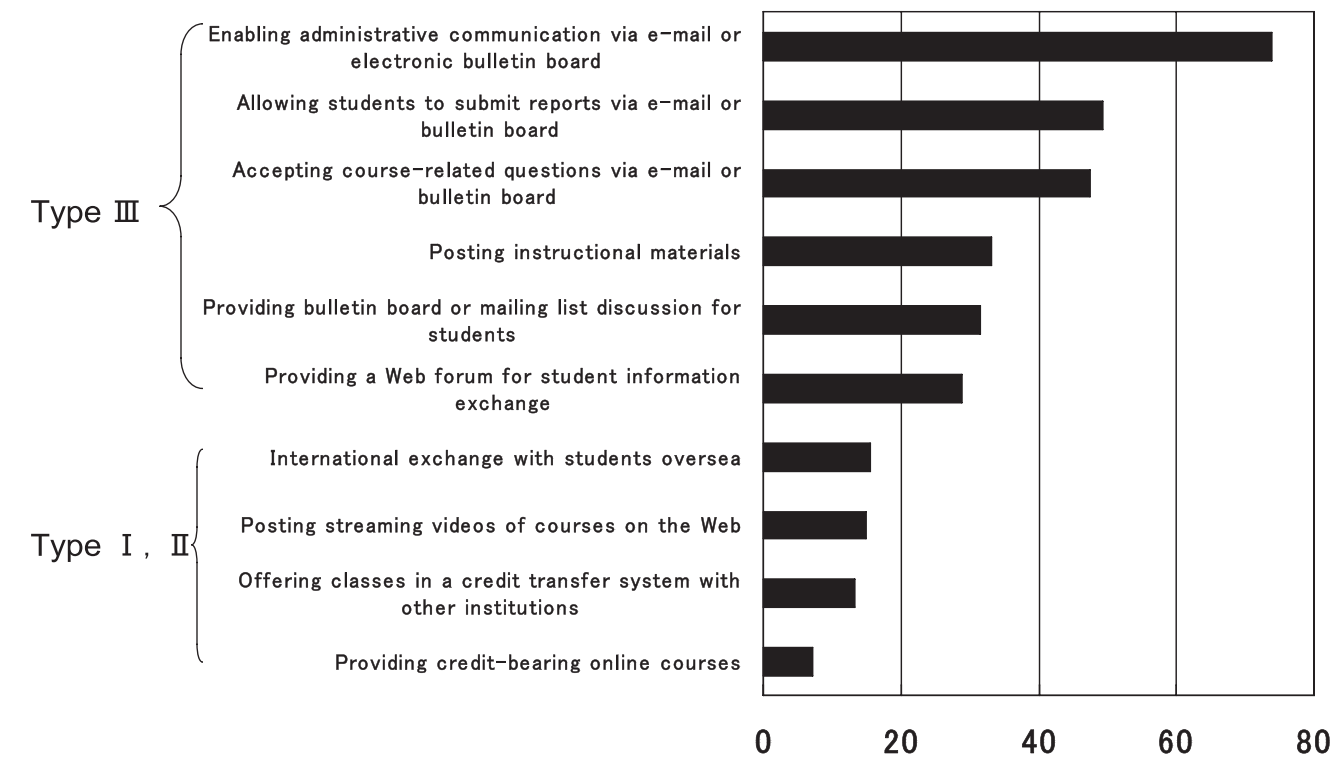

Notes: 1 This figure is drawn up by rearranging the National Survey on ICT Use in Higher Education Institutions in Japan conducted by NIME in line with the classification in this paper.

2 This figure is drawn up according to data for universities in 2003.

Fig.3 Future plan for internet use (“Aggressively planned” (\%)). 
Survey, we can be fairly certain that many universities do not have needs for such activities, while specific universities have such needs.

\section{Analysis based on case studies}

Case studies in this paper have the following two aims: first, to clarify empirically the trend of needs which the Survey indicates; second, to verify that there is any other promoting factor based on the analysis of characteristics in each type.

\subsection{Method}

To investigate actual cases of universities' e-learning programs, two or three cases were selected for each of the three types. To begin with, materials, web sites, and documentary records regarding selected cases were investigated. Next, interviews with the faculty and/or the office staff of selected cases were done. Finally, the results of these were analyzed and studied.

The interviews were done for a month from midJune to mid-July and for a month in September 2004. In the interviews, about 50 questions were set in eight fields: basic information; strategy; platforms and infrastructure; education/learning; students; university personnel and teaching materials; funds and the government; and change, future plans, and obstacles.

The interviewees are professors, associate professors and/or office staffs who take in charge of promotion and management of their e-learning practices.

It should be added here that most of the universities said that there was no suitable answer to certain questions. The questions took up various topics and there are various forms of implementation of e-learning practices for each type, each university may find some questions failed to provide proper answers.

Selected cases are as below.

Type I : Nihon University Graduate School of Social and Cultural Studies

E-School of Waseda University School of Human Sciences

Type II : "iii online" at University of Tokyo Graduate School of Interdisciplinary Information Studies Program of Satellite Lecture to Thailand, Tokyo Institute of Technology E-learning-based Credit Transfer System among National Graduate Schools of Engineering

Type III : Gifu University Kokugakuin University

\subsection{Introduction of cases and characteristics of each type}

This section introduces, for each of the three types, the basic information of each case and analyzes the characteristics of e-learning in each type. This paper treats common features found through the interviews as characteristics of e-learning practices in each type.

\subsubsection{Type I}

Nihon University Graduate School of Social and Cultural Studies, which has a master's course and a doctoral course; and E-school of Waseda University School of Human Sciences, which has a bachelor's course are also e-learning-based correspondence courses for which degrees can be obtained. The entrance examinations for both these courses are very competitive. The latter offers most of the curriculums through the Web site, while the former does not depend heavily on the Web site.

The following are the characteristics of type I that were found through the interviews with the faculty in charge.

\section{A. Strategy}

The common aims of inducting these courses are to improve the quality of education and/or learning and to secure various types of students. They state positively that their main targets are working students.

These courses are both supported by the university authorities although they are belong to only one department. The movement towards the introduction of the e-learning was based on the opinions of the faculty as a start at these two universities, subsequently the heads of department and the presidents took the initiative. It seems reasonable to suppose that university-wide systematic operation was one of the driving force, even though the e-learning practices were introduced only to one department.

\section{B. Platforms and infrastructure}

Both universities use course-management tools which they developed in cooperation with private companies.

To provide e-learning programs, the universities are outsourcing operations related to infrastructure, maintenance, and control to companies.

These things make it clear that the universities already had plans at the time of the introduction of the e-learning programs to reduce burdens on the faculty and administrative organizations in terms of technical matters. 


\section{Education/Learning}

At these two universities, the introduction of e-learning seems to contribute to faculty development (hereinafter referred to as "FD") as a result, even though the e-learning was not introduced as part of FD. In other words, the transparency of classes and instructions was increased by posting teaching materials and/or streaming video of lectures on the web, and the faculty came to have more opportunities to revise their educational methods on their own because of the increased correspondence with working students via e-mail or on electrical bulletin boards.

Strategy for developing so-called "learning object" is now under discussion at Waseda University, while Nihon University makes no special efforts to develop it.

These courses have attracted more applicants than their full quota since they started. The courses started in 1999 at Nihon University and 2003 at Waseda University.

\section{Students}

Both the universities aim principally to provide small-class education. At Nihon University, one instructor teaches less than 10 students in one seminar (around 10 students for an instructor with an exclusive contract with the graduate school) for each grade. These students form a practical class. Waseda University limits the class size to 30 students, and an educational coach (who has at least a master's degree) is assigned to each class to support the faculty. These two universities focus on how to promote and enrich communications between the faculty and students and among students.

At the universities, nearly $90 \%$ of the students have or used to have full-time jobs. In addition, when the universities recruit applicants for admission, they are gradually shifting to target those who have full-time jobs by devising unique entrance-examination systems. The largest number of students is in the 30-39 age range at both the universities. The second largest number of students is in the 40-49 age range at Nihon University, and the third largest number of students is in the 50-59 age range. At Waseda University, the second largest number of students is in the 20-29 age range, while the third largest number of students is in the 40-49 age range.

It seems reasonable to suppose, from what has been stated above, that the universities were able to differentiate their e-learning programs from the conventional correspondence courses. We can say with fair certainty that the e-learning programs at these universities satisfied the needs of people in their 30s and 40s who cannot attend on-campus courses because of their full-time jobs, in spite of their strong desire to learn. It is difficult for such people to continue their learning with conventional correspondence courses, because their jobs tend to be put at a higher priority than studying.

Japanese who live abroad are also enrolled at these two universities. The universities are giving opportunities for such people to receive formal school education in Japanese.

\section{E. University personnel}

Both universities distribute manuals to the faculty and hold training sessions. Furthermore, the universities introduced a system in which technical experts of private companies individually provide full support for the faculty.

These things make it clear that the universities already had plans at the time of the introduction of the e-learning programs to reduce burdens on the faculty and administrative organizations in terms of technical matters.

\section{F. Obstacles}

Waseda University expects that it will have a difficulty in trying to expand its e-learning program. An expected difficulty is the shortage of educational coaches. Educational coach system plays a key role in its program which aims to provide small-class education.

\subsubsection{Type II}

"iii online" at the University of Tokyo Graduate School of Interdisciplinary Information Studies, the Program of Satellite Lecture to Thailand, the Tokyo Institute of Technology, and the E-learning Based Credit Transfer System among the National Graduate Schools of Engineering provide a number of classes for graduate students offered on-campuses through e-learning. Regarding those classes, students can obtain credits mainly by studying through e-learning. Such a program is being utilized by the University of Tokyo for its own students. At the Tokyo Institute of Technology, students of graduate school in Thailand benefit from such a program. In the case of the National Graduate Schools of Engineering, the students of twelve national graduate schools are using such a program under the relevant agreement. The University of Tokyo uses its web site; the Tokyo Institute of Technology uses a communication satellite system and its web site; and the National Graduate Schools of Engineering uses the Space Collaboration System (SCS) or web sites depending on the subjects.

The following are the characteristics of Type II that were found through the interviews with the faculty in 
charge.

\section{A. Strategy}

The aims of inducting e-learning programs vary in this type.

The status and size of organizations which introduce e-learning programs is also different.

The departments are taking the lead in introducing e-learning at the University of Tokyo and the Tokyo Institute of Technology. Introduction of e-learning was not a top-down decision in these two universities. It was initiated by the faculty opinion and then gained the understanding of and the support from the department head. The National Graduate Schools of Engineering are introducing university-wide e-learning programs, and the vice presidents (or persons in equivalent positions) at the universities decided the main policies of the programs through discussions. It seems reasonable to suppose that type II cases also show that organization-wide systematic operation based on support by organization head or deputy head was one of the driving forces, although this factor is shown more clearly by type I cases.

\section{B. Platforms and infrastructure}

The universities use the existing equipment and systems (including the existing school personnel supporting those systems), simpler open source software and/or software which their faculty developed.

The universities are not outsourcing operations. These seem to be because the scale of the e-learning programs offered by the universities is smaller.

\section{Education/Learning}

The universities did not introduce the e-learning programs as part of FD. Subsequently, students became more active in making requests regarding educational methods; for example, they requested the faculty to post teaching materials on the web site in advance. In addition, the transparency of classes and instructions increased by posting teaching materials and/or streaming video of lectures on the web, and the faculty came to have more opportunities to revise their educational methods on their own. FD seems to be promoted as a result.

The three universities are not making special efforts to develop "learning object," and the universities have no special strategies to support the development of the learning object in the future.

\section{Students}

These e-learning programs are basically intended for on-campus students who are formally registered as students of these universities and/or cooperating uni- versities.

As the universities provide education by using methods that could not be offered through conventional classes on campus, some students are enjoying advantages. At the University of Tokyo, full-time worker students, who account for $20 \%-30 \%$ of the total, feel benefit with "iii online" because it has created a useful educational environment [15]. In the case of the Tokyo Institute of Technology, the interviewees evaluate that students in Thailand are appreciating the university's efforts to enable them to take classes of advanced technologies that are not offered in their own graduate schools. In the case of the National Graduate Schools of Engineering, the interviewee evaluates that some students find some attractive classes offered by other universities as they cannot take such classes at their own universities.

The situation mentioned above make it clear that students who find their learning environment improved by taking classes give them credits mainly through e-learning are greatly appreciating the e-learning programs. In other words, the universities have satisfied the needs of such students or cultivated such needs.

\section{E. University personnel}

These universities do not distribute manuals to the faculty or hold training sessions, but on the other hand the University of Tokyo and the Tokyo Institute of Technology introduced a system in which their technical experts individually provide full support for the faculty.

These seem to be because the scale of the e-learning programs offered by the universities is smaller.

\section{F. Obstacles}

The departments are taking the lead in introducing e-learning programs at the University of Tokyo and the Tokyo Institute of Technology. These two universities claimed that the difficulty of obtaining more funds is an obstacle in promoting expansion of e-learning. The University of Tokyo, for example, needs another senior technical expert for expansion. As e-learning expansion would involve spending money, which is not a negligible amount, one can safely state that the expansion of the departments' practices needs to be supported with sufficient funds from the university.

The Tokyo Institute of Technology and the National Graduate Schools of Engineering, which are offering classes in cooperation with other universities, are having difficulty adjusting the systematic differences among universities. The Tokyo Institute of Technology is taking much time to adjust the difference in credit systems between Japan and Thailand. The National 
Graduate Schools of Engineering are taking much time adjusting the differences in academic terms and teaching schedules among universities. These factors are not problematic as long as the universities can take much time because the size of their e-learning programs is not so large. These factors, however, seem to be an obstacle in further expansion of e-learning.

\subsubsection{Type III}

Gifu University and Kokugakuin University use e-learning to supplement class programs or to support learning activities of students on campus. These two universities have installed course-management tools to enable such activities university-wide, namely, posting teaching materials on web sites, sending teachers' messages to students, and using electrical bulletin boards. The faculty can decide whether or not to use these functions. In addition, Kokugakuin University runs a course-management tool that can provide a link to the syllabus system, class registration, and management of attendance records on their web site.

The following are the characteristics of type III that were found through the interviews with the faculty or the office staff in charge.

\section{A. Strategy}

The common aim of inducting these programs is to improve the quality of education and/or learning.

The movement towards the introduction of e-learning was based on the opinions of the faculty or the office staffs as a start at these two universities, subsequently the presidents supported the full-scale induction. Currently, university-wide systematic operations are run, with the center or the educational affairs section taking the lead. As these cases are university-wide programs, it has naturally become a university-wide activity. But the practices at the two universities seem to be showing that the presidents' support is necessary for the full-scale induction.

All faculties, students, and subjects at the universities are registered in course-management tools, and all faculties are ready to use the tools for their classes. But the use of the tools is not compulsive, and each faculty can decide whether or not to use the tools or how to use the tools. On the other hand, the universities are enthusiastic about offering training sessions for the faculty. The training sessions not only teach how to use course-management tools but also show examples of effective use of the tools. Regarding type III, each faculty has different needs for functions, depending on their class styles. As a result, it seems that university-wide e-learning can be introduced smoothly by creating an environment in which all functions can be used and by enabling each faculty to decide how to use the functions.

\section{B. Platforms and infrastructure}

Gifu University uses a course-management tool which a private company developed. Kokugakuin University uses a course-management tool which it developed in cooperation with a private company.

The two universities are outsourcing developmentrelated operations, such as customization of coursemanagement tools. The universities are, however, managing the operation of e-learning in-house. This seems to be because the universities are cautious about outsourcing students' personal information as the course-management tools are used by incorporating educational data on all students into the tools.

\section{Education/Learning}

The universities did not introduce e-learning as part of FD. However, it is expected that the use of coursemanagement tools would encourage improvement of educational methods at Gifu University. In addition, it is understood at Kokugakuin University that activities such as posting teaching materials will lead to promoting FD. The FD committee is planning and offering seminars to present examples of effective use of the tools.

An official evaluation after the introduction of e-learning has not been done at the universities. However, the interviewees expect that it will be an evaluation in terms of improvement of teaching methods used in classes, instead of an evaluation of e-learning programs.

The two universities are not making special efforts to develop the so-called "learning object," and the universities have no special strategies to support the development of the learning object in the future. It seems that the universities do not need to develop the learning object as their main objective is to improve the quality of their on-campus classes.

\section{Students}

These e-learning programs are intended for on-campus students who are formally registered as students of each university.

\section{E. University personnel}

Both universities distribute manuals to the faculty and hold training sessions, but neither of the universities has introduced a system in which technical experts individually provide full support for the faculty. Kokugakuin University would hire such a expert if it had more funds. 


\subsection{Conclusion}

The characteristics of each type of e-learning were analyzed in the above section. This section firstly identifies the differences of the needs for e-learning in each type, and then clarifies other factors which promote the induction of e-learning based on the preceding analyses.

First, the working students, foreign students, and those who study specialized areas are the main beneficiaries of types I and II. These students could not learn sufficiently in the conventional correspondence courses or on-campus courses. It seems reasonable to conclude that the e-learning programs in types I and II are the cases that discovered latent needs of these students. It is not clear to what extent the student market has such needs, though it can be said that for these students that the e-learning programs of types I and II are the effective way to learn.

In all types, the universities did not introduce e-learning services as part of FD; subsequently, the introductions of e-learning contributed to FD and improvement of the qualities of educational contents and methods. It seems reasonable to conclude from this that the introduction of either type of e-learning will have a considerable ripple effect on FD. All three types meet students' requirements because the people who wish, if it's latent, for the improvement of the qualities of educational contents and methods are the students.

All cases focus on a support system for the faculty. The cases with larger scale tend to make use of private company's resources. When we introduce any type of e-learning program, we should try to meet the needs of the faculty, namely, reduction of the burden caused by the induction of e-learning.

It is reasonable to suppose that there are three factors which promote the induction of e-learning in type I : first, support from the university authority on the basis of the president's initiative; second, technical cooperation with private company for reducing the faculty's burden; third, distinct strategy in which the main target of the program is working students. The cases of type II rather have financial difficulties in their expansion. The reason for this is that these cases are hard to have full support from university authority because of their rather small scale.

The development of "learning object" is not treated as important in all types. They give financial priority on hiring teaching staffs for small-class education in type I or on hiring technical experts who individually support the faculty in type II and/or III. The budget for hiring teaching staffs or technical experts would be effective in accelerating the diffusion of e-learning rather than the budget for the development of "learn- ing object.”

\section{Future prospects}

Regarding type III, there are already universities' needs as described in Chapter 4 and students' needs as described in Section 3 in Chapter 5. In addition, there will be further promotion of university-wide introduction of information technologies. These things predict that e-learning programs classified as type III will be most rapidly promoted in the near future.

Regarding types I and II, a key factor for diffusion seems to be how many students such as working students, foreign students and those who study specialized areas can enjoy advantages from e-learning programs. In other words, it is crucial for universities to expand the knowledge of students' potential needs. Next, support from the university authority becomes the driving force.

As the definition of e-learning still varies depending on who is discussing it, it is currently difficult to understand the overall situation of e-learning, even within higher education institutions. One reason for this difficulty may be the ever-changing specifications of e-learning systems caused by continuing technology development. But e-learning actually came to be discussed as an educational method to be used by each university. In such a situation, discussions on how e-learning programs can be used in accordance with the institutional view need be promoted further based on the accumulations of the research results of each laboratory or each project. This paper tries to classify e-learning programs into types, hoping this classification will help promote discussions mentioned above.

The reason this paper mainly focuses on the needs in each type is that e-learning is unlikely to be stably and continuously expanded when there are no needs. The main way of approaching the needs and characteristics in this paper is to interview the faculty and/or the office staff who take in charge of their e-learning practices. Although, this paper can present the needs and characteristics which can not be appeared in figures from various viewpoints based on the real cases in this way, there might be room for argument on objectivity.

The writer will be exploring more objective approaches for further investigation.

\section{Acknowledgements}

When conducting the case studies, I received much valuable information and materials from many professors, assistant professors and office staffs at the Nihon University Graduate School of Social and Cultural Studies, the Administration Office of the Nihon University Graduate School, the E-School of Waseda University School of Human Sciences, the Graduate 
School of Interdisciplinary Information Studies at the University of Tokyo, the School of Engineering and the Global Scientific Information and Computing Center at the Tokyo Institute of Technology, the University of Electro-Communications, the Information and Multimedia Center at Gifu University, and the Shibuya educational affairs section at Kokugakuin University. I would like to express here my cordial gratitude to them, and I am sorry not to list their names for reasons of space.

\section{References}

[1] P. Lynnette, Creating the Virtual Classroom : Distance Learning with the Internet, John Wiley \& Sons Inc, 1997.

[2] O. Satoh, Netto raningu : Jirei ni manabu 21 seiki no kyoiku[Net Learning : Education for 21st Century Learned from Case Studies], Chuo Keizai-Sha, 2001 (in Japanese).

[3] K. Kasaki, Intanetto de MBA/shusigo wo toru [Obtaining MBA/Master's Degree via Internet], Nikkei Business Publications, 2002 (in Japanese).

[4] A. Yoshida, America kotokyoiku ni okeru e raninguNihon he no kyokun[E-Learning at American Higher Education Institutions-Lessons to Japan], Tokyo Denki University Press, 2003 (in Japanese).

[5] K. Araki, Jissen e raningu [Practical E-learning], Mainichi Newspapers, 2002 (in Japanese).

[6] M. Morita, E raningu no jyoshiki[Common Knowledge in E-Learning], Asahi Newspapers, 2002 (in Japanese).

[7] W. Horton, Designing Web-Based Training : How to Teach Anyone Anything Anywhere Anytime, John Wiley \& Sons Inc, 2000.

[8] Proposers of Virtual University Research Forum, Bacharu unibashiti : IT kakumei ga nihon no daigaku wo kaeru[Virtual University : IT Revolution Will Change Japanese Universities], ALC Press, 2001 (in Japanese).

[9] Y. Obara, ICT wo katsuyo shita daigakujyugyou[Univer sity Classes Using ICT], Tamagawa University Press, 2002 (in Japanese).

[10] Advanced Learning Infrastructure Consortium (ALIC), ed., E raningu ga tsukuru kinmirai kyouiku[Education in Near Future Created by E-Learning], Ohmsha, 2003 (in Japanese).

[11] AML II Project at Aoyama Gakuin University Research Institute, E raningu jissenho : Saiba Araiansu no sekai[Practical Method for E-Learning : World of Cyber Alliance], Ohmsha, 2003 (in Japanese).
[12] Consultative Council regarding Global Quality Assurance of Universities, Kokkyo wo koete kyouiku wo teikyo suru daigaku no shitsuhosho ni tuite : Daigaku no kokusaitenkai to gakushukikai no kokusaika wo mezasite [Quality Assurance of Universities Providing Education across Boarders : Aiming to Global Development of Universities and to Globalized Educational Opportunity], 2004 (in Japanese).

[13] Advanced Learning Infrastructure Consortium (ALIC), ed., E raningu hakusho 2003/2004 nennbann[White Paper on E-Learning for 2003/2004], Ohmsha, 2003 (in Japanese).

[14] National Institute of Multimedia Education, National Survey on ICT Use in Higher Education Institutions in Japan, 1999.

National Institute of Multimedia Education, National Survey on ICT Use in Higher Education Institutions in Japan, 2000.

National Institute of Multimedia Education, National Survey on ICT Use in Higher Education Institutions in Japan, 2001.

National Institute of Multimedia Education, National Survey on ICT Use in Higher Education Institutions in Japan, 2002.

National Institute of Multimedia Education, National Survey on ICT Use in Higher Education Institutions in Japan, 2003.

[15] T. Mochizuki, "Riyosha annkeito ni yoru iii online no hyoka [The evaluation of iii online by the user questionnaire]," E raningu manejimento: Daigaku no chosen [Management of e-learning: University's challenge], J. Nakahara and T. Nishimori, eds., pp.105126, Ohmsha, 2003 (in Japanese).

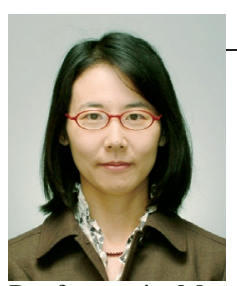

Keiko WATANABE

Keiko WATANABE spent over 10 years, as a planner of Japanese educational system at the Ministry of Education, Culture, Sports, Science and Technology after receiving B.A. in Law from the University of Tokyo. Then she joined NII as an Associate Professor in May 2003. Her research interest includes the impact of expanding e-Learning on the current educational system and management of universities and/or schools. 